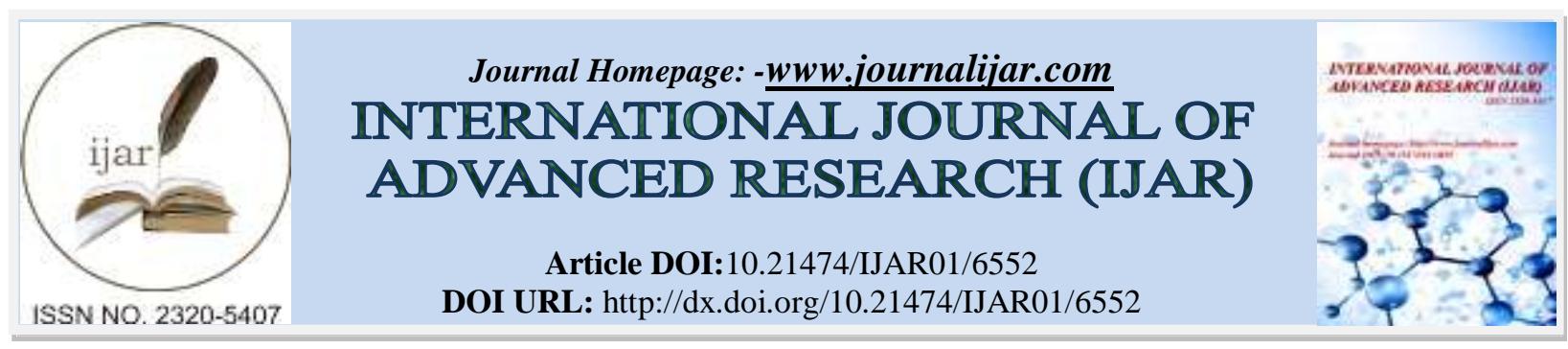

RESEARCH ARTICLE

\title{
THE STUDY OF THE IMPLEMENTING OF THE BALANCED SCORECARD IN PUBLIC ORGANIZATIONS AS A TOOL OF PERFORMANCE CONTROL:"CASES FROM OCP GROUP".
}

BotainaMjidila, Youssef El wazani and MalikaSouaf.

Research Team in management and performance of organizations in the public, private and the social economy (EMAPES), ENCG Agadir, Morocco.

\section{Manuscript Info}

Manuscript History

Received: 16 December 2017

Final Accepted: 18 January 2018

Published: February 2018

Key words:-

management control, performance management, balanced scorecard, new public management, OCP group.

\section{Abstract}

In an economic context marked by hostility and turbulence, it is now a priority to question the need to put in place much more effective performance management tools within Moroccan public organizations. Our paper will focus on a recently developed tool called the Balanced Scorecard (BSC) (Norton \& Kaplan, 1992) and will study the check box of one of the world leaders in the phosphate market et sesdérivés; qui est OCP group. The goal is to analyze the different steps to be undertaken for the implementation of this tool in the Moroccan public organizations within the framework of New Public Management, following the case of an organization with economic, financial, social, societal and environmental objective.

Copy Right, IJAR, 2018,. All rights reserved.

\section{Introduction:-}

The results of a firm depend on several factors beyond the classical financial factors (Norton \& Kaplan, 2001). The human capital and the proper functioning of the internal process are key elements for the firms objectives achievement.

For an organization like the OCP group SA, one of the world leaders who is involved in the production of phosphate and its derivative products, the establishment of a set of indicators that take into account all the dimensions of the organization is a needed to ensure that the group is on the right path. The achievement of this objective has of the principles of management, which are based on the sharing of objectives and transparency at all levels in order to measure the contribution of each staff in the overall strategy of the group.

The establishment of a balanced scorecard for the control of the performance of the axis Daoui-SidiChennane, implies first of all a very good understanding of the group, its role, its customers as well as its environment. Then, have a clear vision of its development strategy.

\section{Research problem:-}

To ensure its position in the world market for the production of phosphate and derived products and achieve a comprehensive performance that meets the needs of all stakeholders, the Group OCP SA and more specifically the axis Daoui-SidiChennane the mining site of Khouribga must have a tool for performance steering able to identify all the aspects of performance .Yet, the system of current pilotage of the group is not able to adapt to it. This, was for us a strong motivation to staff the Group OCP SA and more specifically the axis DaouiSidi-Chennane a tool of 
strategic control able to control all aspects of the performance. It is the design of the Balanced Scorecard. Of where our main question of research:

The Balanced Scorecard Could it constitute, the tool of strategic control which responds best to the specificities of the OCP group and its pilotage requirements of the performance?

The present work will respond to the following research questions:

- How can we drive a company via the Balanced Scorecard, in order to achieve the desired performance?

- What link can-there have between the strategy and the annual objectives of production?

- How to integrate the objectives of the extraction and processing of phosphate in the Balanced Scorecard?

In this perspective, the objectives of the development of the BSC for the axis ChennaneDaoui-Sidi have for purpose:

- Explain the vision, values and mission of the group with a view to give the employees a comprehensive understanding of the strategy of the group and to involve them in the strategic approach;

- Quantify the performance of a comprehensive way i.e. according to the different perspectives;

- Establish a tool for dialog and communication with the collaborators on the contribution of each of them in the achievement of the strategic objectives and the achievement of the performance;

- Ensure the success of the whole of the strategic plans developed and have the capacity to respond in the event of need;

-Put in place strategic plans beyond the financial dimension.

To do this our article will focus on the study of the contribution of the BSC for the OCP group and its design stages according to the model proposed by Norton and Kaplan, we begin by defining the conceptual framework and then present the empirical results of the work carried out within the group.

\section{Cconceptualadre:}

In this part, we start by presenting the conceptual framework of the study, including details on the dashboards as a tool of control of the performance and of the specific characteristics to Dashboards prospective.

\section{The instrument panel: tool for performance steering}

Book (2008) has defined the instrument panel as an information tool on the future and which illuminates the objectives not achieved by accounting and which also allows to project into the future the consequences of decisions and offers a global vision on the activities and priorities of the Organization. This being said, it is also to clarify that there is no instrument panel type, they do not exist as tools to follow with more or less efficiency The degree of achievement of the objectives set (Dupuis, 1991).

A dashboard is mainly constituted of a set of indicators to apprehend the objectives of the organization, follow their degree of achievement and to evaluate the means implemented to achieve these objectives.

An indicator, Main Ingredient a dashboard, is defined as a presentation quantified to an economic variable for a given level of responsibility (Gibert, 1980).

The authors (Meyssonnier\& RasolofoDistler, 2008; Saghroun\& Eglem, 2007; Choffel and Meyssonnier, 2005; Poincelot\& Wegmann, 2005, Norton \& Kaplan, 2001) cite two types of indicators to measure the performance, it is including financial and non-financial indicators. While stating that the financial indicators have a direct link with the result and the financial profitability of the organization and are based on the accounting data and financial matters.They are easy to interpret and to quantify and are also used to compare in time of similar entities. The financial indicators the more frequent whose turnover, the gross margin, the net result and the cost of returns.

For the non-financial indicators, rather they are qualitative indicators that quantitative.

\section{the specificities of the Balanced Scorecard:-}

According to Kaplan and Norton (1998), the non-financial indicators are complementary to the financial indicators which serve rather to control the actions of the medium and long term.

For the Balanced Scorecard, said also looking forward, Kaplan and Norton (2001) have proposed indicators that go beyond the financial aspect and integrate other non-financial indicators.It is presented first of all as a balanced 
system to measure the overall performance covering the whole of the value creation process and do not focusing not only on the results. Of this fact, the BSC is considered as a set of indicators grouped within four strategic axs, and who have to each other the causal links.

\section{1) Presentation of the results on the contribution of the Balanced Scorecard:}

At this level, we present the results obtained by our exploratory study, on the case of the OCP group, which has been conducted with officials of management control and accounting.

\section{1) The analysis of the system of current pilotage}

The thorough analysis of the system of current pilotage shows that there is a panoply of malfunctions that can be summarized as follows:

In term of forecast cycle and declination of the strategic objectives, the Group OCP does not establish a formal way a strategic plan, communicated to all operational levels on a regular basis, and it does not adopt the exercises to develop an operational plan in the medium term, although it is foreseen in the management cycle of the group, therefore, the budget is not the declination of a vision the medium term. In addition the Group OCP designs its quarterly forecasts as of budget updates, whose horizon is limited to 31 December of the current year.

These weaknesses restrict the ability of the Group to guide and reorient its decisions of industrial policy, investment, mode of financing which require to have carried out a multi-year forecast and whose impact is higher than the budget horizon annual.

In term of managerial responsibility, the Group OCP does not define in a manner explicit and shared the perimeters of financial responsibilities (and managerial) as well as the criteria of the performance associated What is translated by:

- A dilution of responsibilities of managers, as well as the impossibility and the difficulty of judging the actual performance by center of responsibilities;

- A lack of focus on the key objectives of the responsibility centers, to the detriment of the overall performance of the Group;

- The heterogeneity of tools and reportingof presents the risk of inconsistency between the various performance areas, this partitioning is reinforced by the absence of links between indicators. We are talking about several reportingof which contain the same information, but each is entered independently.

We note that the responsibility of the States of reporting of management is not centralized in the control of management (instrument panel CEO under the responsibility of the Cabinet of the President, reportingof sales and the sale price under the responsibility of the Directorate of Trade, the instrument panel HR under the responsibility of the Directorate Human Capital ...). This lack of uniqueness of the circuit for the feedback of information has for consequence of inconsistencies between the different reportingof: Each domain is the subject of "reporting " specific.

Also among the limits that represents the system of current pilotage one distinguishes, the measure to ex post facto of the performance through reporting tools, the indicators selected are not elements of measures to simulate in any reliability the trajectory of the strategy.

The absence of indicators determinants of performance in terms of process innovation, the skills development and growth and which are established on the basis of the mission of the company, and there is also the time of production of the reportingof which are too long of the fact of the dependence of the reporting of the closing accounting usually it is $\mathbf{J}+20$.

\section{2) The contribution of the BSC:}

According to the interviews conducted with the managers of technical cells methods and planing who use the dashboards as a tool for performance steering (instrument panel FIG /MK/E), the use of the latter is seen as satisfactory in terms of sufficiency of axs and indicators, however this tool marks a lack at the level of the axis human resources that appears neglected any time the application of a dashboard is more balanced would be more decisive than that of the tool in application PRESENT, something which is possible at the level of the axis and which presents a more in term of performance . 
Among the obstacles that can declare themselves during the implementation of this tool is the non-collaboration of staff.

Finally the introduction of the Balanced Scorecard is considered more effective than the Management Dashboard, such is the subject of our research.

\section{3) discussion on the contribution of the BSC for the system of existing pilotage}

After having analyzed the system of current pilotage and the inadequate content of dashboards and existing reporting, it appears that the BSC takes into consideration of Indicators Financial extra that are well linked to the strategy (satisfaction of employees, turnover, high potential, index of satisfaction of employees...etc.).

Of this fact, the Balanced Scorecard enables you to determine a causal link between the different perspectives financial and non-financial. It is considered not as a reporting tool classic, but well an approach of construction of multidimensional objectives of the performance and translation of these objectives in term operational.

In effect, all current indicators constitute a good basis for the assessment of the performance of the axis to study and identify the vision and the strategy of the axis which derives from that of the group, to identify the key factors for success and to identify the indicators that we can deploy to measure and evaluate the key success factors.

2) Presentation of the results on the approach of the implementation of the BSC as a tool for performance steering within the OCP

We start, in a first step, by release the internal diagnostic External and of the environment of the studied structure.

\section{1) The internal analysis}

To analyze the internal environment of the OCP group, we retain as a tool for strategic diagnosis the value chain of the OCP group SA.

The representation of Group OCP in value chain allows you to model the organization of activities of the company in their environment and to make the link between the strategy of the group and the perimeters of responsibility of the various actors. The decomposition of activities covers, on the one hand, the perimeters dedicated functional to the Poles, but also of functional perimeters shared. The central part corresponds to the operational activities of the Group; as well as to support activities and governance of the Group. This structuring of the Group in Responsibility Centers is based on a CPC by destination, the aim of which was to analyze the outcome of the Group by nature of charges and products and by major activity component the value chain of the Group: production, distribution, marketing, research \& development, support functions / administrative.

\section{1) The external analysis:}

The analysis of the external environment will be made on the basis of the model PESTEL

Table 1:-Assessment of the analysis PESTEL

\begin{tabular}{|l|l|}
\hline Aspects & The indicators \\
\hline Policies & Political stability; \\
& - Tax Policy favoring the activity to \\
& The export (17.5 Of IS) for the mining company of export; \\
- Free Trade Agreement with the USA, EU.
\end{tabular}




\begin{tabular}{|l|l|}
\hline In technology & The creation of a directorate dedicated to the \\
Research and innovation; & - Strategic Position of NICTS in the policy of the State: \\
& - Digital Morocco 2013 \\
& - Initiative Morocco Innovation \\
& - Géni Program. \\
& - Dynamic of the market of NICT \\
\hline Environmentally friendly & Compliance with environmental standards \\
& International (Kyoto Protocol; standard of the World Bank) ; \\
& - Accession since 2007 to Responsible Care; \\
& - Establishment of a system first. \\
& - Adherence to the principle of the IFA; \\
& - Environmental projects. \\
\hline Disclaimer & The legal framework governed by the Ministry of \\
& The energy and mines; \\
& - The Group OCP has a monopoly of \\
& Research and exploitation of phosphates in Morocco (Dahir 6 Jumada 1338- \\
& 26/01//1920). \\
& - OCP its adheres to several groups \\
& International (IFA, AFA, IPNI...). \\
\hline
\end{tabular}

\section{3) Summary of strategic analysis (SWOT analysis)}

The SWOT analysis allows you to summarize the strategic diagnosis through the four angles (Opportunity/Threats, strengths/weaknesses).

The table below summarizes the analysis of the environment.

Table 2:-Summary of the analysis.

\begin{tabular}{l}
\hline Opportunities \\
-Transformation of the OCP in SA; \\
- International Market favorable; \\
- Strategy Plan Morocco Green; \\
- Progressive closures of mines exploited for \\
environmental reasons and redirection of volumes of \\
export to the domestic market. - The \\
implementation of agricultural support policies; \\
- The increase in the demand for the products which \\
will be approximately $50 \%$ between 2000 and $2030 ;$ \\
- Increase the level of life of the population; \\
- Increase of the world population to the Horizon 2050 \\
of $42 \%$ or 2.6 billion to reach $\$ 9.2$ billion \\
- Increase in cultivated areas (+58,6million ha); \\
- The Growth of the world demand for phosphate \\
fertilizer $+3 \%$ to the Horizon 2017 .
\end{tabular}

fertilizer $+3 \%$ to the Horizon 2017 .

\section{Threats}

-High volatility of the raw materials markets;

- The Industry phosphatie remains deeply cyclic;

- The influx of production capacity massive to the horizon 2012 (15 to 20 projects are committed, of which $95 \%$ are integrated): spectacular entrance of a new competitor with its mega project: JALAMEED;

- Consolidation of the sector through mergers acquisitions (United States) and new alliances upstream and downstream (United States, India);

- The majority of future projects will encompass the entire value chain da the mine in the production of fertilizer in passing by the acid (integrated producers)

- Evolution of the exchange rate;

- Environmental Risks (contamination of the sub-soil and wadis, the pollution of the environment and the risk of erosion of the dikes; - Risks related to potential social conflicts.

\begin{tabular}{l|}
\hline The forces \\
\hline Pilotage system current: \\
- Positive approach of the present pilotage system \\
through the establishment of a planning process (Plans \\
Annual Action /divisions). \\
Deployment process of the Strategy: \\
-Translation of the strategy in term operational. \\
- Clarity of the mission of the OCP toward its staff; \\
- Participation in the development of the plans of \\
action;
\end{tabular}
Weaknesses

- Internal communication around the planning process and staff involvement in all stages

- The lack of Measurement of consistency between the objectives and the means selected;

- The need of the mechanisms of rigorous follow-up of the planning process including the strategic projects;

- Performance Measurement System is not enough;

- The need to strengthen the reflection concerning: the satisfaction of needs of clients; the profitability (cost of 
- The transposition of strategic actions in operational actions;

- A Better strategic visibility for the staff of the OCP (staff and managers). -The adequacy of the Organization with the strategy

- The integration of the Key support features and pilotage;

- Promotion of the decentralization and the responsibility;

- The establishment of an organization site.

-The system of ownership of the strategy of the Staff

- Good understanding of strategic directions concerning the staff; returns); HRM; the IF; the environment; performance; the flexibility of the production and communication at the level internal and external.

- The need for improvement of the strategy

Concerning the staff via 2 levers:

-Strengthen internal communication;

-Call into question the present remuneration system for a variability objective and fair.

-Need a proper policy for the management of human resources.

- Weaknesses at the level of the strategic alignment and budget.

- Weakness of the inconsistency between the plans of actions and budgetary resources.

\section{4) Clarification of the strategy of theaxis}

We turn, via this step, to clarify the strategy of the axis, of the fact that in the approach to the implementation of the Balanced Scorecard, the vision is the starting point for any strategic pilotage and we synthesize this through the recovery of the card 's overall strategic extraction process-treatment of the axis DaouiSidichennane, which is nothing other than the consolidation of all the strategic maps of each axis . 


\subsection{1) Strategic Map The overall treatment process}

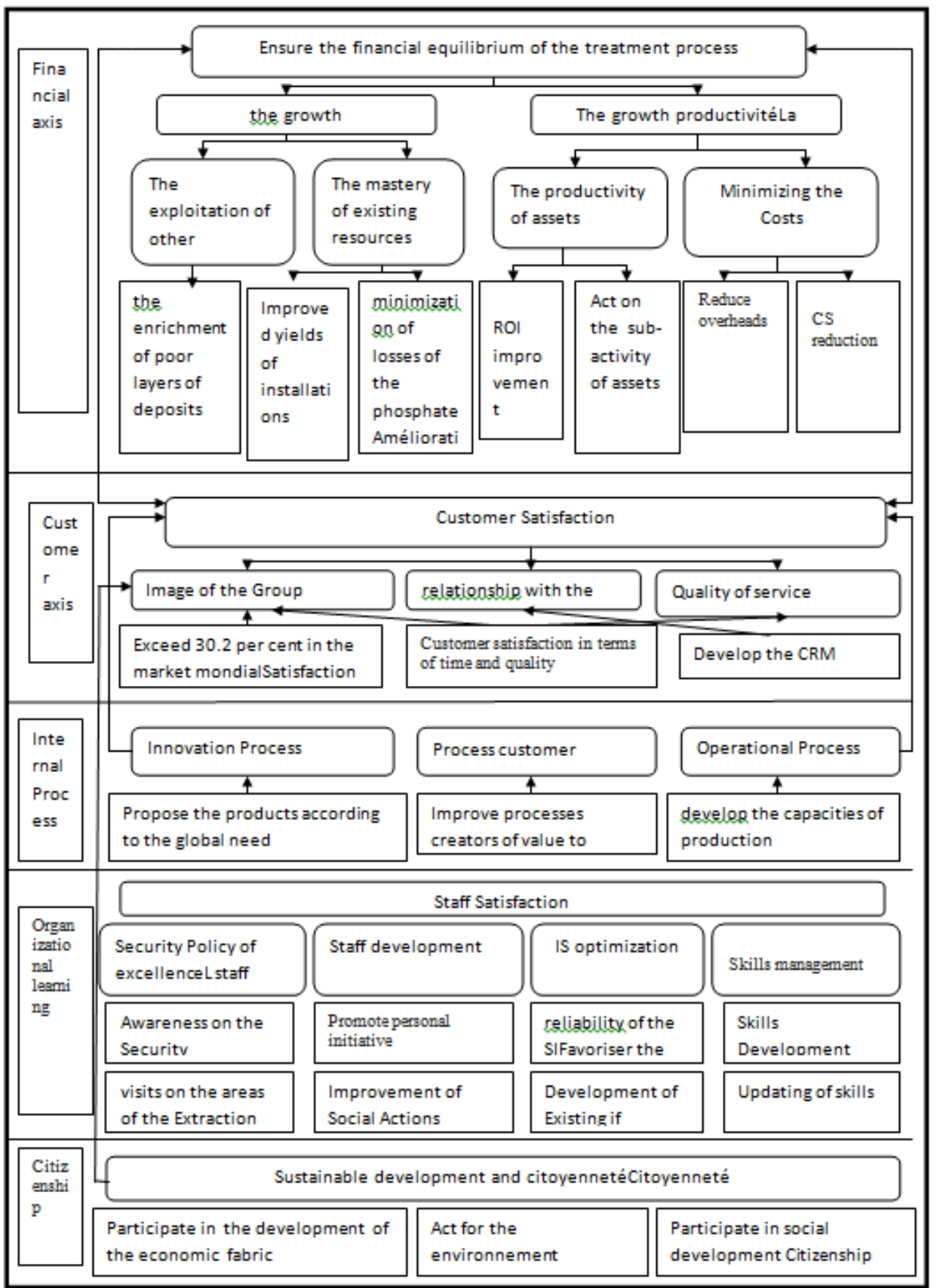

\subsection{2) reading of the strategic map:}

The development of the strategic map main mission is to make the strategy of the company understandable through its translation into objectives presented in the different axs: financial, customers, internal process, organizational learning and citizenship.

The strategic map of the process of treatment of phosphate at the level of the axis Daoui-SidiChennane consists of five levels consisting of the five axs and the strategic objectives of each axis which are presented by cause-effect relationships. These relations are horizontal between the strategic objectives of a same axis vertical and between the five axs. 
In effect, the reading of the strategic map allows you to determine the following links between the objectives of the different axs:

The first level of the BSC is the financial axis which constitutes the main generator of financial wealth. Of this fact, that the process of treatment of phosphate ensures the sustainability of its financial equilibrium and so that it can preserve for the Group the position of world leader in the production of phosphate and its derivatives, there must be sufficient financial resources to be able to finance its process of exploitation, to fund all investment projects and meet by the following the needs of clients.

At this stage, two levers of actions have been retained, it is in the growth of turnover through the minimization of losses of phosphate during transport to the Factories (launching of the project of the establishment of pipelines in 2014) or during the different stages of treatment, the improvement of the yields of the facilities and the enrichment of poor layers of the deposits. This growth must be coupled by an argument of the productivity and this through the productivity of assets and the minimization of costs.

For the axis client, three objectives were set aimed at the satisfaction of customers in times and quality, the development of the management of the relationship with the customer, and the exceeding of $30.2 \%$ in the share of the world market in order to improve the image of the group in the world market.

The axis internal process, as well, contains the strategic objectives related to innovation, customer relationship management and operational efficiency. It is the proposal of products according to the global needs, improve the creative processes of value among the clients in order to improve a relationship of trust with them; to retain and develop the capacity of production.

The existence of effective process allows you to generate the wealth and satisfy the customers as well as to ensure the sustainability and the financial balance. Of this fact, the achievement of these objectives requires motivated staff.

At this level, the axis Organizational Learning contains four strategic objectives. It is the management of skills through the safeguarding and improvement of existing skills, the optimization of information systems to provide powerful information, then, it is the promotion of the Initiative staff and the improvement of the degree of social actions in favor of collaborators in order to follow a policy of security through the establishment of a permanent way of training, awareness raising meetings on security, as well as visits to the areas of treatment in order to propose the best working conditions.

The last axis of the BSC C is the axis sustainable development and citizenship, in this axis three strategic objectives were identified: participation in the development of the economic fabric, the protection of the environment and the participation in social development. These objectives have for mission the improvement of the image of the group in the economic fabric of Morocco and in the sector of phosphates.

Once the strategic map developed, we will begin the next phase which consists in the choice of indicators to measure the implementation of the strategic objectives.

\section{5) Development and deployment of the Balanced Scorecard}

The choice of indicators is an important step in the approach to the development of the BSC. They are tools to assess, communicate the performance achieved in relation to the expected results, and to determine if the deployment of the strategy is done in a correct manner.

After declining strategic objectives and indicators of the process by axis of the BSC, we draw the Balanced Scorecard.

The objective is to translate the strategic directions of the group and to communicate to all the staff of the extraction process and guide, as well, all efforts toward the achievement of the strategic objectives of the group. 
Table 3:- Balanced Scorecard synthesized the extraction process- treatment Daoui axis

\begin{tabular}{|c|c|}
\hline \multicolumn{2}{|c|}{ Balanced Scorecard The process extraction-treatment - DAOUI axis } \\
\hline Strategic Objectives & Indicators to measure \\
\hline \multicolumn{2}{|l|}{ Financial axis } \\
\hline The minimization of costs & - $\quad$ Cost to the tonne extracted \\
\hline The productivity of assets & $\begin{array}{ll}- & \text { The rate of implementation of investment } \\
\text { - } & \text { The rate of return of facilities } \\
\text { - } & \text { Return on Investment }\end{array}$ \\
\hline The mastery of existing resources & $\begin{array}{ll}- & \text { The rate of return of facilities } \\
- & \text { Flow of conveyor }(\mathrm{m} 3 / \mathrm{h}) \\
\text { - } & \text { Rate of availability of facilities }\end{array}$ \\
\hline The exploitation of other resources & $\begin{array}{l}\text { Extraction of the content of the GLP of the quality } \\
\text { BT, TBT }\end{array}$ \\
\hline \multicolumn{2}{|l|}{ Customer axis } \\
\hline Satisfaction of clients in times and quality & $\begin{array}{ll} & \text { Rate of claims of customers } \\
- & \text { Rate of orders shipped within the time limits } \\
- & \text { Rate of compliance of commands }\end{array}$ \\
\hline $\begin{array}{l}\text { Protrusion of } 30.2 \text { per cent in the global } \\
\text { market }\end{array}$ & $\begin{array}{ll}\text { - } & \text { Numbers of Contracts Processed } \\
\text { - } & \text { Number of foreign investors that sits at the level of the hub } \\
\text { of Jorf. }\end{array}$ \\
\hline $\begin{array}{l}\text { Develop the customer relationship } \\
\text { management }\end{array}$ & $\begin{array}{ll}- & \text { The punctuality of deliveries } \\
\text { - } & \text { Quality of the products delivered } \\
- & \text { Reliability rate of CRM } \\
\end{array}$ \\
\hline \multicolumn{2}{|l|}{ Axis internal process } \\
\hline $\begin{array}{l}\text { Propose products according to the global } \\
\text { needs }\end{array}$ & $\begin{array}{l}\text { Rate of compliance quality delivered by report } \\
\text { Quality controlled. }\end{array}$ \\
\hline Improve the process creation of values & Ratio of specific consumption diesel (, explosive, electricity ) \\
\hline Develop the capacity of production & $\begin{array}{ll}- & \text { Products Volume (volume processed and shipped by } \\
\text { - } & \text { Quality source and merchant) } \\
- & \text { Rate of implementation of projects for the opening of mines } \\
- & \text { Rate of achievement of the purchases of land }\end{array}$ \\
\hline \multicolumn{2}{|l|}{ Axis Organizational Learning } \\
\hline The improvement of the skills & $\begin{array}{ll}- & \text { Number of training provided/year } \\
- & \text { (Budget devoted to training) } \\
- & \text { Rate of improvement by agent } \\
- & \text { Rate of satisfaction to the development } \\
- & \text { By profession or by category } \\
- & \text { Rate of rotation of staff }\end{array}$ \\
\hline The vitality of the Staff & $\begin{array}{ll}- & \text { Rate of productivity } \\
- & \text { Rate of absenteeism per employee (numbers of day } \\
- & \text { Of absence/employee) } \\
- & \text { Rate of Turn over. }\end{array}$ \\
\hline Reliability of the information system & $\begin{array}{ll}- & \text { Numbers of reliability check established } \\
- & \text { Number of request made (number of information } \\
- & \text { Given by the system). }\end{array}$ \\
\hline Have a security policy of excellence & $\begin{array}{ll}- & \text { Number of work accidents and trip } \\
- & \text { Number of training sessions and meetings of } \\
- & \text { Awareness } \\
- & \text { Rate of frequency } \\
- & \text { Rate of gravity. }\end{array}$ \\
\hline \multicolumn{2}{|l|}{ Citizenship axis } \\
\hline $\begin{array}{l}\text { Participate in the development of the economic } \\
\text { fabric }\end{array}$ & $\begin{array}{l}\text { Volume of activity generated with businesses } \\
\text { National, regional and local. }\end{array}$ \\
\hline Take Action for the environment & - $\quad$ Rate of achievement of the Project Green mine; \\
\hline
\end{tabular}




\begin{tabular}{|l|l|}
\hline & $-\begin{array}{l}\text { Level of pollution by factory. } \\
\text { Numbers of trees planted }\end{array}$ \\
\hline Participate in social development & $-\quad \begin{array}{l}\text { Rate of achievement of the citizens' actions (committed } \\
\text { budget })\end{array}$ \\
$-\begin{array}{l}\text { Number of complaints filed against the axis in the framework } \\
\text { of the activity of the site }\end{array}$ \\
\hline
\end{tabular}

Table 4:- Estimate of the calculation of the indicators the ingredients of the Balanced Scorecard.

\begin{tabular}{|c|c|}
\hline \multicolumn{2}{|c|}{$\begin{array}{l}\text { Estimate of the calculation of the indicators the ingredients of the Balanced Scorecard Balanced Scorecard } \\
\text { The process extraction-treatment - daoui axis }\end{array}$} \\
\hline The indicators & Calculation \\
\hline Cost per tonne extracted & $\begin{array}{l}\mathrm{C}=\Sigma \text { expenditure charged on the axis / Tonnages excerpts } \\
\text { ( Average Cost current }=80 \mathrm{DHS} / \text { Source: analytical balance ) } \\
\text { Objective: passage has } 63 \mathrm{dhs} / \text { tonne extracted }\end{array}$ \\
\hline Rate of realization of investments & $\begin{array}{l}\text { I rate = budget incurred monthly or annual / The investment } \\
\text { budget }\end{array}$ \\
\hline Rate of yield of facilities & $\mathrm{TRG}=$ rate of availability $*$ Rates of PACE $*$ Rate of quality \\
\hline Rate of availability & $\mathrm{TD}=$ ( Opening times - Judgments) $/$ Opening times \\
\hline Rate of pace & $\mathrm{TA}=$ actual speed of production / Reference speed \\
\hline Rate of quality & $\begin{array}{l}\text { TQ= ( Number of units produced - Number of defective units) } \\
\text { / Number of Units Produced }\end{array}$ \\
\hline King & Loss or gain / I \\
\hline Flow of feeder & Quantity of phosphates in $\mathrm{m} 3 / 1 \mathrm{~h}$ \\
\hline Rate of customer complaint & Number of Claim / Number of Clients \\
\hline Rate of orders shipped within the time limits & $\begin{array}{l}\text { Number of orders shipped within the time limits / The number } \\
\text { of commands }\end{array}$ \\
\hline Rate of compliance of commands & $\begin{array}{l}\text { The number of commands consistent / The number of } \\
\text { commands }\end{array}$ \\
\hline $\begin{array}{l}\text { Rate of compliance quality delivered } \\
\text { by quality report ordered. }\end{array}$ & $\begin{array}{l}\text { The number of commands to be non-compliant with the } \\
\text { requested quality }\end{array}$ \\
\hline Ratio of Specific Consumption & $\begin{array}{l}\text { The one speaks of the minimization of the costs in terms of the } \\
\text { improvement of the process via the creation of other methods of } \\
\text { operation, currently we are talking about the discovery to sky } \\
\text { (use of the explosive). } \\
\text { Cost of the specific consumption engaged (real cost) / Estimated } \\
\text { Cost }\end{array}$ \\
\hline $\begin{array}{l}\text { Rate of implementation of projects for the } \\
\text { opening of mines }\end{array}$ & $\begin{array}{l}\text { Now they are talking about the area lehlasa and OULED fares } \\
\text { which are in the course of preparation for opening. } \\
\text { Number of Projects / Number of projects envisaged or planned }\end{array}$ \\
\hline Rate of achievement of land purchases & $\begin{array}{l}\text { Number of Land Purchased / Number of Possible land to the } \\
\text { purchase }\end{array}$ \\
\hline Rate of improvement by agent & $\begin{array}{l}\text { Number of agent in training / The number of agents } \\
\text { Number of training / Number of global training }\end{array}$ \\
\hline Rate of productivity & Production / The number of \\
\hline Rate of absenteeism per employee & Numbers of day of absence / Employee \\
\hline
\end{tabular}

6) Recommendations for the deployment of the BSC:

The construction of the balanced scorecard is not the end of the design. It must be used and integrated into the system of management of the company.

The communication of the need of the Balanced Scorecard and its importance in all levels, as well as all of the strategic objectives must be launched and shared in order to achieve the desired performance and to ensure the strategic control of the different objectives. 
The communication of the BSC allows to reach a set of objectives:

- To make known the vision to all employees concerned (the problems encountered, the solutions envisaged, the means to implement to take the corrective measures),

- Help to anticipate and resolve the difficulties encountered;

- Ensure the consistency between the approaches adopted and the changes suffered;

- Introduce new actions to cope with the changes;

The Balanced Scorecard is much more than a simple table of indicators linked. It is a real management system which acts on several facets. It is a tool of strategic control. Its design is only the beginning of a great and long process of strategic management which will allow the company to ensure the proper implementation of its strategy.

\section{Conclusion:-}

The Balanced Scorecard is one of the most used tools in the management and control of the performance and of the strategy of enterprises. Put at the disposal of the service management control of the axis Daoui-SidiChennane such a tool, assumes follow a certain design approach.

But before embarking on this design approach, we proceeded to a diagnosis of the pilotage system group current OCP SA via the information system and dashboards existing, a part, and on the other hand the presentation of the strategic diagnosis of the Group through different tools diagnostics to know the model of PESTEL for the external environment and the value chain for the internal environment to finally make a synthesis via the SWOT matrix.

Subsequently, we have proposed the methodological approach of design of the BSC in the context of our Axis of study which is to clarify the vision and the strategy of the axis in question, the Make it understandable and generate the accession of all the parties concerned for its realization.

In order that the axis Daoui-SidiChennane could fly its performance and apply the strategy established by the group. He described its strategy in the strategic objectives involving all its components.

Through the five axs of the BSC (financial, customers, internal processes, organizational learning and sustainable development and citizenship), we chose relevant indicators help to measure the performance and piloting the implementation of the strategy of the group studied.

Aware of the new character of this management tool and changes that its use requires, we have made recommendations that will accompany the axis in question in the use of her BSC.

Our proposal for a Balanced Scorecard for the axis ChennaneDaoui-Sidi, is certainly not the final version to use in a permanent manner. The BSC of the axis must be updated each time that there will be a change at the level of the strategic vision of the group and its objectives. 


\section{Bibliography:-}

1. ALAIN Fernandez (2010), " The new dashboards for Managers ". Editions of Organization.

2. BARILLOT Pascal (2000), "Control of the performance and business strategy : the Example

3. The table deBord Forward", Management.

4. Book,H (2008). What prospects for research in management control. Control Finance strategy - Vol. 11, offseries, p. 177 - 191.

5. Book, H ( 2010), Management Control, 9th ed. Paris: PUF Edition.

6. Book, H (2011), Management Accounting, 9th ed. Paris: Économica Edition.

7. CROSET Pascal (2012), " The transformation of the Office Chérifien des Phosphates ", Dunod, Paris.

8. DOHOU Angèle, Berland Nicolas (2010), "Measurement of the overall performance of firms

9. ".Accounting and the environment, France.

10. Dupuis, J (1991), the control of management in public organizations, Paris: university presses of the FRANCE ( $P U F)$.

11. GERMAIN Christophe (2003), "Instrument panel". E- theque.

12. Gibert, $\mathrm{P}(1980)$, the control of management in public organizations. Paris: Editions

13. Of Organization.

14. Kaplan, R. S. and D. P. Norton (1992). "The Balanced Scorecard - measures that drive

15. Performance." Harvard Business Review 70(7/8): 172-180.

16. Kaplan \& Norton (1998). The Balanced Scorecard. Paris: Edition of organization.

17. Robert Kaplan and Norton David (2001), " How to use the Balanced Scorecard ", editions of organization.

18. KAPLAN, Norton (2003), " The Balanced Scorecard ", editions of Organization".

19. LEROY, Frédéric (2012), " the strategies of the Firm ", 4nd edition, Dunod.

20. LORINO Philippe (1991), " the control of strategic management-the management by the activities ", Editions Dunod.

21. MOTTIS Nicolas (2006), " the control of management ", 2nd edition, EMS editions.

22. Voyer Pierre (1999), " dashboards for management and performance indicator"; 2ND EDITION; presses of the University of Quebec.

23. WIGMAN Grégory (2000), "The dashboards strategic: comparative analysis of a model North American and a Swedish model". Management review.

24. $\square \square$ internal documentation:

25. Annual Reports 2014,2015 .

26. Manual for the management of the OCP group SA.

27. Review of Industrial Performance (April 2013). 